06

\title{
Волновые эффекты корреляции элементарных деформационных актов при высокотемпературном нагружении алюминия и его сплавов
}

\author{
(C) В.А. Плотников, С.В. Макаров
}

Алтайский государственный университет, 656049 Барнаул, Россия

e-mail: plotnikov@phys.asu.ru

Поступило в Редакцию 20 мая 2019 г.

В окончательной редакции 20 мая 2019 г.

Принято к публикации 21 октября 2019 г.

Проведены эксперименты по деформированию алюминия и его сплавов в условиях механического нагружения и высоких температур. Установлено, что накопление деформации в этих условиях протекает как монотонный и скачкообразный процесс, сопровождающийся монотонной и импульсной акустической эмиссией. Установлено, что основной вклад в накопление деформации вносят деформационные скачки, сопровождающиеся не только акустической эмиссией, но и осцилляцией механического напряжения. Осцилляция механического напряжения свидетельствует о быстропротекающих процессах упрочнения и разупрочнения металлических материалов. Спектральный анализ потока сигналов акустической эмиссии свидетельствует, что в ходе накопления деформации деформируемый объем представляет собой естественный резонатор, на котором осуществляется преобразование первичных сигналов акустической эмиссии в низкочастотный спектр стоячих акустических волн, осуществляющих корреляцию элементарных деформационных актов в макроскопическом масштабе, где масштаб корреляции определяется длиной стоячей волны.

Ключевые слова: деформационные скачки, акустическая эмиссия, стоячие акустические волны.

DOI: 10.21883/JTF.2020.04.49092.200-19

\section{Введение}

Считается очевидным, что пластическое течение, особенно большие пластические деформации, не могут быть описаны как аддитивный вклад отдельных дислокаций [1]. Неслучаен в этой связи интерес к описанию пластической деформации, учитывающий корреляции в системе дислокационного ансамбля, характеризующие деформационное поведение системы в сильно неравновесных условиях.

Эксперименты по деформированию металлов свидетельствуют [2], что в ходе пластической деформации в направлении растяжения распространяются очаги деформации, в которых локализовано пластическое течение. Из этих экспериментов сделан вывод, что процесс деформации охватывает структурные уровни разного масштаба: от микроскопического масштаба до мезоскопического и макроскопического масштабов. Локализация неустойчивости кристаллической структуры при пластической деформации кристаллов для классической трехстадийной зависимости $\sigma-\varepsilon$ (здесь $\sigma-$ механическое напряжение, $\varepsilon-$ относительная деформация) связывается с процессом самоорганизации дислокаций [3]. Учет фактора самоорганизации позволяет сформулировать фундаментальный вывод о том, что наблюдаемое в экспериментах многообразие деформационного поведения и дислокационных структур есть результат эволюции дислокационного ансамбля путем развития коллективных и кооперативных явлений и их пространственной упорядоченности, проявляющейся в формировании линий и полос скольжения [3].

Для реализации элементарного акта пластического сдвига необходим разрыв межатомных связей вдоль линии дислокации, осуществляемый как результат действия тепловых флуктуаций и механических напряжений [4]. Наиболее эффективно этот процесс осуществляется в условиях действия механических напряжений при высоких температурах, переводящих кристаллическую среду в слабоустойчивое состояние. Состояние системы, именуемое слабоустойчивым, может быть связано с состоянием атомного ансамбля в поле механических напряжений и тепловых флуктуаций, совместное действие которых позволяет преодолеть потенциальный барьер процесса разрыва связи [4,5]. Для осуществления элементарного акта разрыва связи, в том числе и при пластической деформации требуется положительная флуктуация энергии, локализованной в малом коллективе взаимодействующих атомов [4]. Моделирование таких ситуаций в атомной системе позволило установить, что сильная флуктуация энергии атомов может представлять собой достаточно устойчивое, динамическое состояние [6].

В условиях слабоустойчивого к внешним воздействиям состояния кристаллической среды корреляция в системе структурных дефектов, определяющих процесс самоорганизации дислокационного ансамбля, приобретает первостепенную роль в эволюции структуры деформируемого металла. Одним из признаков корреляции элементарных деформационных актов является эффект 
скачкообразного накопления деформации при термомеханическом нагружении алюминия. Однако такой подход не учитывает явление акустической эмиссии и ее роли в процессах пластической деформации, хотя в условиях термомеханического нагружения металлических материалов на протяжении всего процесса нагрева наблюдается эмиссия акустических сигналов [7]. Наблюдается двоякий характер накопление деформации - монотонный и скачкообразный и два варианта проявления акустической эмиссии - монотонный и импульсный (дискретный) [8-10]. Показано, что амплитуда акустического сигнала может характеризовать корреляцию в ансамбле элементарных излучателей, т.е. в ансамбле элементарных деформационных актов $[8,9]$.

Активная роль акустической эмиссии в процессах пластической деформации и разрушения обсуждается давно $[11,12]$. В этих обсуждениях скачкообразная деформация и дискретная акустическая эмиссия трактуется как проявление пространственно-временно́й упорядоченности движения дефектов в кристалле [13]. Так, в рамках модели автоакустической эмиссии кристалл представляет собой автоколебательную систему (естественный резонатор в наших терминах), для которой характерно возбуждение колебаний, а микроскопические процессы пластической деформации происходят кооперативно и самосогласованно [11]. Скачкообразная деформация и связанные с ней высокоамплитудные акустические импульсы свидетельствуют не только о пространственновременно́й упорядоченности движения дефектов, но и об акустическом волновом механизме локализации деформации в макроскопическом масштабе, где масштаб локализации определяется длиной стоячей акустической волны, сформированной путем преобразования первичных сигналов акустической эмиссии на естественных резонаторах деформируемого объема [14-16].

В настоящей работе представлены результаты анализа процессов скачкообразного накопления пластических деформаций с позиций акустической волновой корреляции и активации элементарных деформационных актов в алюминии и его сплавах при высоких температурах.

\section{Методика экспериментов и материалы}

Исследование процессов накопления деформации в металлах осуществляли в условиях мягкой схемы нагружения. В мягкой схеме нагружения фиксируется деформация как функция параметров (механическое напряжение, температура). В экспериментах образец нагружался сдвиговым напряжением, и фиксировалась сдвиговая деформации при нагреве его до предплавильных температур.

Объектом исследований был выбран технический алюминий и алюминиево-магниевый сплав АМг6. Из пластины сплава АМг6 вырезали образцы в виде стержней длиной $300 \mathrm{~mm}$, в которых были сформированы области локализации деформации диаметром $4 \mathrm{~mm}$ и

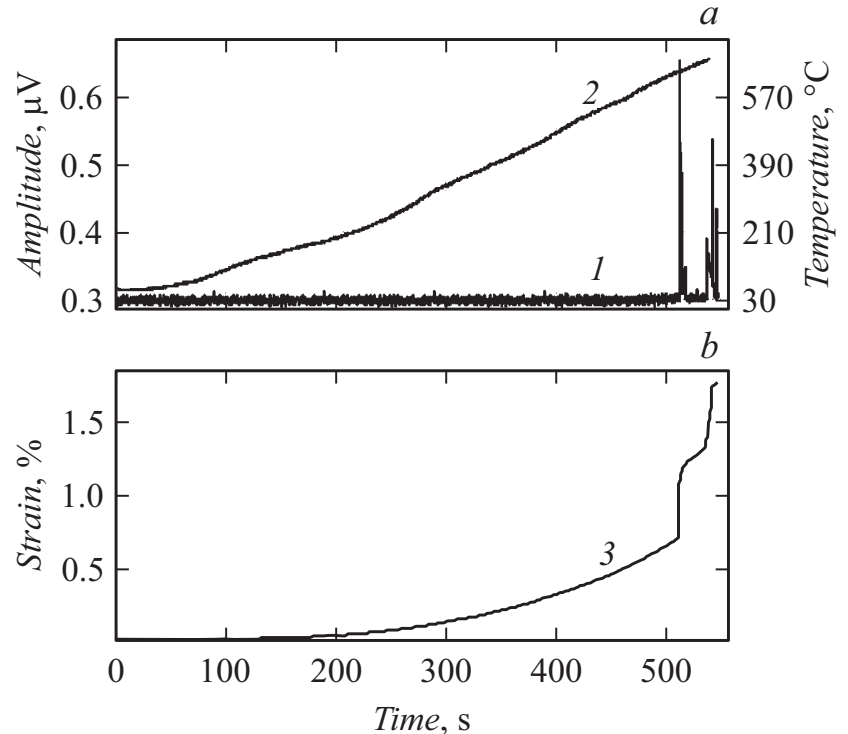

Рис. 1. Акустическая эмиссия в ходе монотонного и скачкообразного накопления деформации в алюминии при механическом напряжении вблизи предела текучести в неизотермическом термомеханическом цикле: 1 - зависимость среднеквадратичного напряжения акустической эмиссии от времени, 2 - температурная кривая, 3 - зависимость накопленной деформации от времени.

длиной $30 \mathrm{~mm}$. Большая часть стержня выполняла роль волновода. Такой же конфигурации были изготовлены образцы из алюминия. Образцы предварительно отжигали в течение $1 \mathrm{~h}$ и охлаждали с печью: сплав АМг6 при температуре $500^{\circ} \mathrm{C}$, алюминий - при температуре $600^{\circ} \mathrm{C}$. В табл. 1 приведены механические свойства и структурное состояние исследуемых металлических материалов. Механическое нагружение, измерение деформации, температуры и среднеквадратичного напряжения акустической эмиссии проводили с помощью установки, схематичное описание которой приведено в [17].

\section{Экспериментальные результаты}

При нагреве образцов в условиях нагружения постоянным сдвиговым напряжением величиной около предела текучести наблюдается монотонное и скачкообразное накопление деформации, сопровождающееся монотонной и высокоамплитудной (импульсной) акустической эмиссией. Как показано на рис. 1, каждый скачек деформации коррелирует с высокоамплитудным импульсом акустической эмиссии. Фактически полная деформация представляет собой сумму скачкообразных актов, разделенных монотонными участками, вклад которых в общую деформацию мал. Характерно, что по мере повышения температуры время монотонного накопления деформации уменьшается, т. е. накопление деформации представляет собой некоторый квазипериодический процесс смены деформационных скачков монотонны- 
Таблица 1. Механические свойства и структурное состояние сплава АМг6 и алюминия

\begin{tabular}{|c|c|c|}
\hline \multicolumn{2}{|c|}{ Предел текучести } & \multirow{2}{*}{ Структурное состояние } \\
\hline при кручении, МРа & при кручении, МРа & \\
\hline АМг6 - 85 & АМг6 - 170 & $\begin{array}{c}\text { Двухфазное состояние: твердый раствор } \mathrm{Mg} \text { в } \mathrm{Al} \\
\text { и интерметаллическая фаза } \mathrm{Mg}_{5} \mathrm{Al}_{8}\end{array}$ \\
\hline $\mathrm{Al}-15$ & $\mathrm{Al}-30$ & Поликристаллический агрегат \\
\hline
\end{tabular}
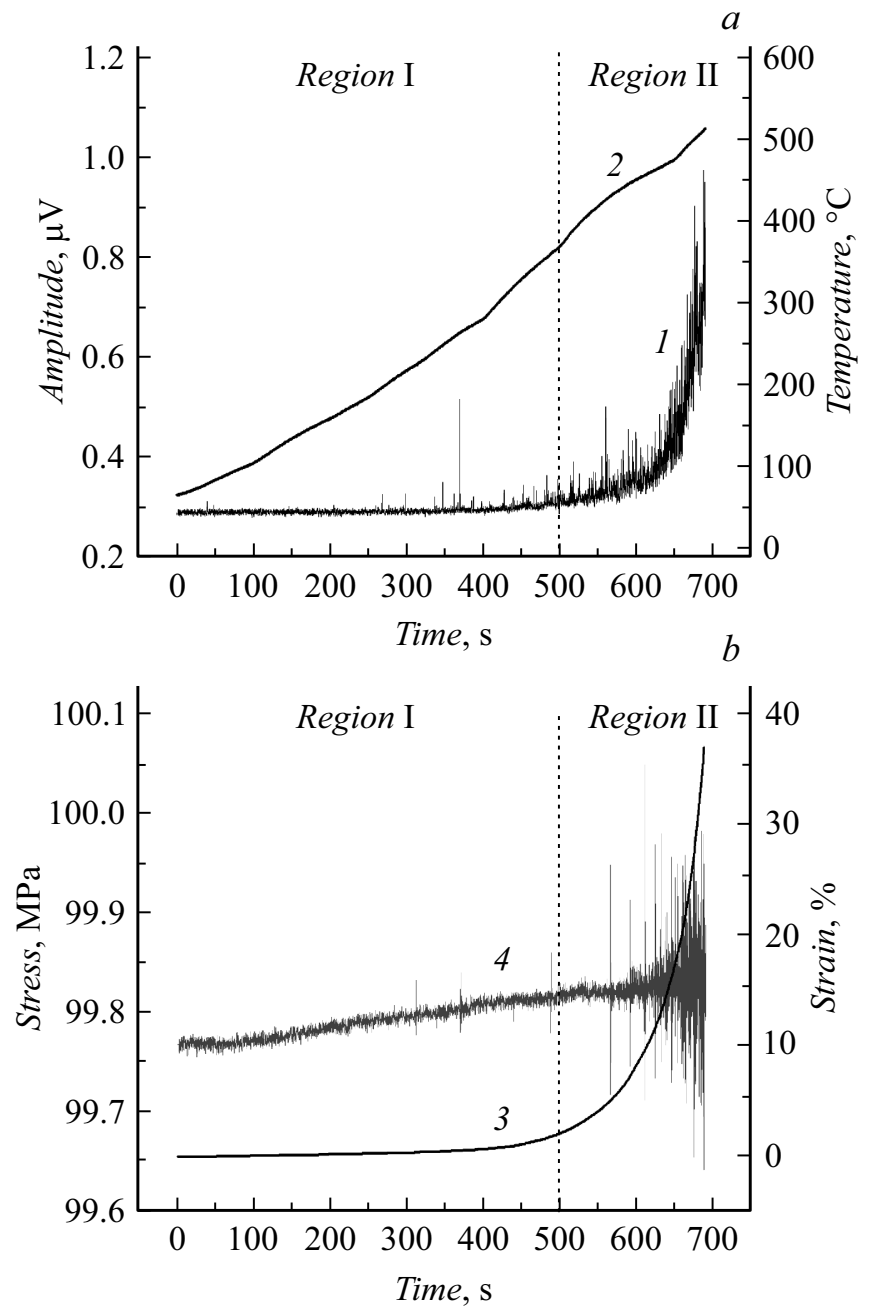

Рис. 2. Акустическая эмиссии (1), температура (2), накопление деформации (3), механическое напряжение (4) при нагреве образца АМг5 в условиях действия постоянной нагрузки $100 \mathrm{MPa}$. Штриховая линия делит весь процесс накопления деформации на две области: в области I скорость накопления мала; в области II скорость накопления существенно выше.

ми актами. Отсюда можно ожидать, что есть условия термомеханического воздействия, когда эти временные промежутки будут ничтожны.

Как показали эксперименты, характерной особенностью высокотемпературного нагружения алюминия и алюминиево-магниевых сплавов является осциллирую- щий характер механического напряжения. На рис. 2 показано, что в условиях действия нагрузки около $100 \mathrm{MPa}$ и нагреве до $500^{\circ} \mathrm{C}$ накопление деформации в АМг6 представляет собой переход от монотонного низкоскоростного (область 1) к высокоскоростному (область 2) процессу. Следует заметить, что этот переход сопровождается существенным возрастанием среднеквадратичного значения акустической эмиссии.

\section{Обсуждение экспериментальных результатов}

Осциллирующий характер механического напряжения в области 2 (рис. 2) свидетельствует, что накопление деформации и акустическая эмиссия в действительности представляют собой дискретные, но в эксперименте неразрешимые, деформационные и акустические акты. То есть в области 2 наблюдается множественный характер скачкообразных деформационных актов, вносящих основной вклад в общую деформацию сплава. Кроме того, что более важно, осцилляции механического напряжения свидетельствуют о квазипериодичности процессов упрочнения и разупрочнения, протекающих в деформируемом объеме материала. Действительно, хорошо известен эффект динамической рекристаллизации, заключающийся в разупрочнении металла, подвергаемом деформации при высоких температурах, в ходе которого параллельно осуществляются два конкурирующих процесса - упрочнения и разупрочнения $[18,19]$. Отмечается, что особенно периодичность процессов упрочнения и разупрочнения хорошо проявляется в ходе ползучести металлических материалов.

Анализ скачкообразной деформации и эффектов корреляции элементарных деформационных актов проведем, рассмотрев спектр потока сигналов акустической эмиссии. На рис. 3 представлены спектры акустической эмиссии, характерные для монотонного и скачкообразного накопления деформации.

Согласно приведенным на рис. 3 данным, спектральная плотность сигналов акустической эмиссии в системе образец-волновод представлена системой дискретных линий, распределенных в низкочастотном диапазоне частот $30-120 \mathrm{kHz}$. Дискретный характер спектральной плотности сигналов акустической эмиссии свидетельствует, что наша система образец-волновод представляет собой резонансную систему, состоящую из несколь- 
Таблица 2. араметры акустических резонаторов системы образец-волновод

\begin{tabular}{|c|c|c|c|c|}
\hline \multirow{3}{*}{$\begin{array}{c}\text { Номер } \\
\text { резонанса }\end{array}$} & \multirow{3}{*}{$\begin{array}{c}\text { Частоты, } \\
\text { Нz }\end{array}$} & $L, \mathrm{~mm}$ & $L, \mathrm{~mm}$ & $L, \mathrm{~mm}$ \\
\hline & & \multicolumn{3}{|c|}{ Волна } \\
\hline & & продольная, $k=1, V=6420 \mathrm{~m} / \mathrm{s}$ & сдвиговая, $k=1, V=3040 \mathrm{~m} / \mathrm{s}$ & сдвиговая, $k=1, V=2530 \mathrm{~m} / \mathrm{s}$ \\
\hline 1 & 35700 & 89.9 & 42.6 & 35.4 \\
\hline 2 & 41500 & 77.3 & 36.6 & 30.5 \\
\hline 3 & 44500 & 72.1 & 34.2 & 28.4 \\
\hline 4 & 45800 & 70.1 & 33.2 & 27.6 \\
\hline 5 & 47900 & 67.0 & 31.7 & 26.4 \\
\hline 6 & 49400 & 65.0 & 30.8 & 25.6 \\
\hline 7 & 54000 & 59.4 & 28.1 & 23.4 \\
\hline 8 & 67400 & 47.6 & 22.6 & 18.8 \\
\hline 9 & 86000 & 37.3 & 17.7 & 14.7 \\
\hline 10 & 88500 & 36.3 & 17.2 & 14.3 \\
\hline
\end{tabular}

Примечание: приведены данные для двух значений скоростей сдвиговых волн: 3040 m/s — скорость при комнатной температуры, 2530 m/s — скорость при температуре около $600^{\circ} \mathrm{C}$.
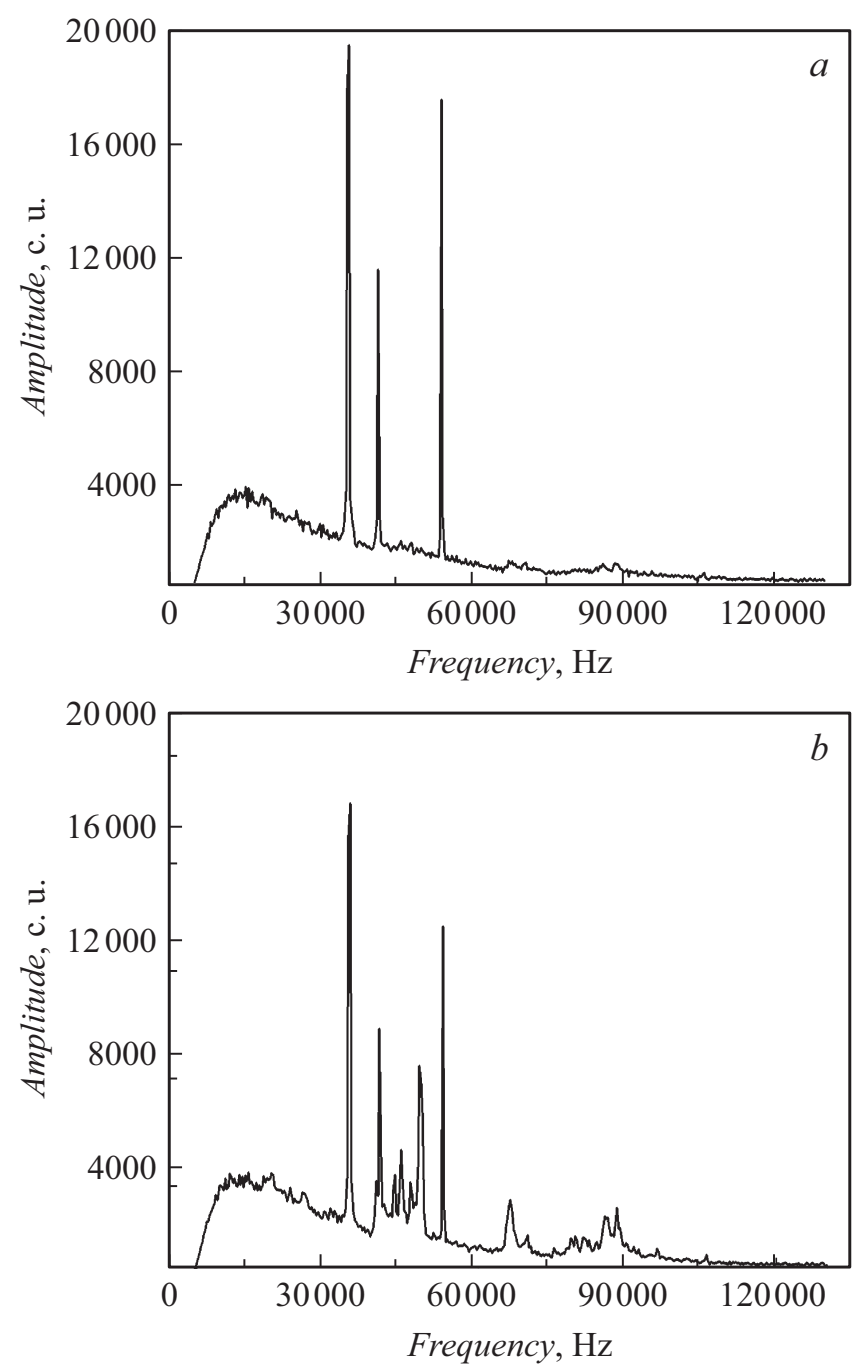

Рис. 3. Спектральный состав потока сигналов акустической эмиссии при накоплении деформации: $a-$ в области I; $b-$ в области II. ких резонаторов. По этим резонаторам распределяется колебательная энергия как акустического шума, так и первичных элементарных излучателей акустической эмиссии в виде стоячих продольных и поперечных волн. Отметим, что в ходе скачкообразного накопления деформации спектральная плотность мощности акустических сигналов значительно сложнее, чем спектральная плотность для монотонного участка, что обусловлено существенным возрастанием плотности потока сигналов акустической эмиссии в области 2. Хорошо разрешаются максимумы спектральной плотности на частотах $48-54 \mathrm{kHz}$ и $67-90 \mathrm{kHz}$, характеризующие формирование достаточно устойчивых стоячих волн в области локализации деформации, т.е. в области концентрации напряжений длиной $30 \mathrm{~mm}$. Согласно табл. 2, для резонатора длиной около $30 \mathrm{~mm}$ на частотах $48-54 \mathrm{kHz}$ возможны резонансы на поперечных волнах, а на частотах $67-90 \mathrm{kHz}$ - резонансы на продольных и поперечных волнах.

В табл. 2 приведены геометрические размеры 10 резонаторов при фиксации 10 спектральных линий. Расчет геометрических параметров резонаторов осуществляли исходя из условия формирования стоячей волны $2 L=k \lambda$ ( $\lambda$ - длина волны, $k$ - порядок спектра, принимающий значения 1,2 , и т.д.).

Так как стоячая волна имеет макроскопический масштаб, то и активация элементарных деформационных актов осуществляется в макроскопическом масштабе в некоторой совокупности плоскостей скольжения, благоприятно ориентированных по отношению к колебательным смещениям стоячей волны. В условиях слабоустойчивого состояния кристаллической решетки колебательные смещения активируют элементарные сдвиги, которые будут представлять собой коррелированный макроскопический ансамбль элементарных деформационных актов, формирующих макроскопический скачек деформации. В свою очередь коррелированные деформа- 
ционные сдвиги генерируют акустические сигналы, компенсирующие потери колебательной энергии стоячих волн в резонаторе, связанным с областью локализации деформации.

Таким образом, стоячая акустическая волна определяет макроскопический масштаб корреляции элементарных деформационных сдвигов. В то же время стоячая волна естественно определяет и область локализации деформации, которая представляется и как область концентрации источников акустической эмиссии.

\section{Заключение}

Осциллирующий характер механических напряжений свидетельствует о протекании быстрых квазипериодических процессов упрочнения и разупрочнения кристаллической среды в ходе высокотемпературного накопления деформации.

Проведенный анализ низкочастотного спектра акустической эмиссии при высокотемпературной пластической деформации алюминия свидетельствует, что его дискретный вид обусловлен перераспределением колебательной энергии первичного акустического сигнала по резонансным колебаниям стоячих волн резонаторов. В слабоустойчивой кристаллической решетке активация элементарных деформационных сдвигов осуществляется в результате совместного действия статических сил, тепловых флуктуаций и динамических сил стоячих акустических волн в некотором объеме, связанным с длиной стоячей волны, определяющей макроскопический масштаб корреляции. Коррелированные деформационные сдвиги генерируют акустические сигналы аномально высокой амплитуды, компенсирующие потери колебательной энергии системы стоячих волн в естественном резонаторе, формируемым областью локализации деформации, что поддерживает корреляцию элементарных деформационных актов.

\section{Конфликт интересов}

Авторы заявляют, что у них нет конфликта интересов.

\section{Список литературы}

[1] Рыбин В.В. Большие пластические деформации и разрушение металлов. М.: Металлургия, 1986. 224 с.

[2] Зуев Л.Б., Данилов В.И., Горбатенко В.В. // ЖТФ. 1995. Т. 65. Вып. 5. С. 91-103.

[3] Малыгин Г.А. // УФН. 1999. Т. 169. № 9. С. 979-1010.

[4] Регель В.Р., Случкер А.И., Томашевский Э.Е. Кинетическая природа прочности твердых тел. М.: Наука, 1974. $560 \mathrm{c}$.

[5] Макаров С.В., Плотников В.А., Потекаев А.И. // Изв. вузов. Физика. 2011. Т. 54. № 3. С. 47-54.

[6] Слуцкер А.И., Михайлин А.И., Слуикер И.А. // УФН. 1994. 164. № 4. С. 357-366.
[7] Плотников В.А., Макаров С.В. // Письма в ЖТФ. 2008. Т. 34. Вып. 6. С. 65-72.

[8] Макаров С.В., Плотников В.А., Потекаев А.И. // Изв. вузов. Физика. 2011. Т. 54. № 3. С. 47-54.

[9] Макаров С.В., Плотников В.А., Потекаев А.И. // Изв. вузов. Физика. 2013. Т. 56. № 6. С. 23-30.

[10] Плотников В.А., Макаров С.В. // ФММ. 2008. Т. 105. № 4. C. $424-430$.

[11] Бовенко В.Н. // Изв. АН СССР. Металлы. 1984. № 1. C. $129-137$.

[12] Бовенко В.Н. // Известия АН СССР. Серия физическая. 1986. T. 50. № 3. С. 509-512.

[13] Шибков А.А., Золотов А.Е., Желтов М.А., Денисов А.А., Гасанов М.Ф. // ФТТ. 2014. Т. 58. № 5. С. 848-855.

[14] Макаров С.В., Плотников В.А., Потекаев А.И. // Изв. вузов. Физика. 2014. № 4. С. 14-18.

[15] Макаров С.В., Плотников В.А., Потекаев А.И. // Изв. вузов. Физика. 2014. № 7. С. 81-86.

[16] Макаров С.В., Плотников В.А., Потекаев А.И. // Изв. вузов. Физика. 2014. № 12. С. 14-18.

[17] Макаров С.В., Плотников В.А. // Деформация и разрушение материалов. 2015. № 10. С. 21-25.

[18] Горелик С.C. Рекристаллизация металлов и сплавов. М.: Металлургия, 1978. 568 с.

[19] Лубенеи С.В. // ФТТ. 2002. Т.44. Вып. 1. С. 72-78. 